\title{
Effect of Property of Concrete Material during Construction on its Subsequent Durability
}

\author{
Xinyi Chen \\ Department of Mechanical, Chemical and Materials Engineering, University of Cagliari, Cagliari, Italy
}

\begin{abstract}
With the sustainable development of human society in recent years,the existing engineering technology has been changing and improving in architectural engineering field in order to satisfy the development of modern architectural engineering. For so long, however, problems on durability in engineering structure, especially the partial deciding effect of property characterized by concrete material on its durability, as a popular topic have been discussing and analyzing by researchers all over the world. In addition, finding an effective method to change property of concrete material to enhance its durability is a project that lots of researchers would like to do over their lifetime. To comprehensively reveal the unique laws between the property of concrete material during construction period and its durability in the following days, the origin of concrete material must be researched as the first object to understand the early property of concrete material, which is of the foundation to clearly control the research on its durability from macro perspectives.
\end{abstract}

Keywords: Construction Period; Concrete; Durability.

\section{TECHNOLOGY ROUTE}

1.1 Test for early performance of concrete

Under the different construction environment and conditions, curing conditions for concrete are not the same. Therefore, when early property was measured for test-piece of concrete, its environment and possible behaviors, which might appear, had to be taken into account overall [1].

\subsection{Test for subsequent durability of concrete}

After setting hard, air permeability is able to be measured effectively for concrete test-piece with water vapor permeability tester. By the measurement, air permeability characterized by concrete after setting hard will be controlled effectively, which is of an excellent criterion to estimate the subsequent durability of concrete material. In addition, testing equipment for chloridion, as known as RCT, was applied in measuring chloridion corrosion of test-pieces. Steel corrosion was measured to a certain degree. They are the main tests that decide the durability of concrete test-pieces at subsequent stage [2].

\subsection{Test for concrete micro-structure}

For the measurement on concrete test-pieces, exploration and analysis based on macro-perspective is not enough and observation for micro-structure is necessary. With scanning electron technology, micro-structure of concrete test-pieces at different ages will be detected absolutely, under different construction environments and curing conditions. By studying different micro-images, pore structures inside concrete test-pieces in different environments and curing conditions are revealed and, flaws and their distribution features of test-pieces formed in process of setting hard at early age are found out [3].

\section{TEST SCHEME}

\subsection{Materials and construction scheme}

In the article, all concrete test-pieces used in this research take No. 42.5 port-land cement and, ordinary gravel and quartz stone with grain size $20 \mathrm{~mm}$ and tea sulfonic acid as water reducing agent. However, taken into account the difference between construction condition and curing condition, experimental materials are divided into four groups to research further.

\subsection{Test methods}

1) Property of mixed concrete

According to the relative test standards of mixed concrete, slump and entrapped air content were measured for concrete test-piece in the experiment firstly. In the experiment, the instruments such as slump cone, direct-reading air entrainment meter were used frequently in the whole process. 


\section{2) Permeability of Concrete}

Air permeability is of a vital index factor that decides the later durability of concrete. Measuring for permeability of concrete therefore is of a necessary step in the experiment in this article. Permeameter is the basic instrument used. According to the corresponding standard steps in measuring permeability,in this article, concrete samples were put on the permeameter firstly and the permeameter was fixed secondly. Air flushing state was kept by permeameter after adjustment. Air drum was used for air injection to permeameter slowly and injection was stopped until 100mb.Meter reading was recorded for every minute based on the permeameter.

\section{EXPERIMENTAL RESEARCH ON EFFECT OF CONSTRUCTION CONDITIONS ON EARLY MATERIAL PROPERTY}

In addition to the measuring on slump, entrapped air content permeability, in this article, concrete samples were studied and analyzed under different curing conditions, in order to confirm the rules between curing environment in construction and different properties of concrete in the early and subsequent stage. During the experiment, relative parameters of concrete before and after setting hard were analyzed in detailed, such as entrapped air content and slum etc before and strength and elasticity etc after setting hard. To give an objective and scientific experiment, in the article, differential experiment was applied by taking into account different ages of concrete in the experimental process, in order to make comparison, which was helpful to clearly and totally know the property at early-age. In this chapter, after the experiment about effect caused by early material property of concrete, effect of concrete vibrating and curing conditions etc on its material property of concrete will be revealed scientifically, which provides us practical basis and theoretical reference to judgment on subsequent durability.

\subsection{Property of Fresh Mixed Concrete}

During the research and analysis on four groups of concrete sample with different curing conditions, fresh mixed concrete showed excellent material property on entrapped air content and slump. In the experiment, however, it found that concrete vibrating in a way significantly affects their entrapped air content. If concrete vibrating is sufficient, their entrapped air content is same whether the mixing batches are same or not. On the contrary, if concrete vibrating does not exist, the entrapped air content is higher than the former although the same effectiveness can be achieved. In other words, concrete vibrating is of a necessary condition that decreases entrapped air content in concrete. Only the concrete vibrating is excellent can air bubbles entrapped in concrete be broken, which decreases the entrapped air content and enhances tightness of concrete.

\subsection{Hydration heat of concrete}

In the analysis about hydration heat of concrete, it revealed that rate of hydration heat of concrete increases fast, which may increase nearly $15 \%$, without concrete vibrating condition. In other words, concrete vibrating is the factor decreasing rate of hydration heat that prevents concrete from internal cracking caused by hydration heat. In the construction, therefore, sufficient concrete vibrating is necessary to keep concrete durability it should have.

\subsection{Early-age shrinkage of concrete}

Respect to early-age shrinkage, water-tightness is of a primary step. Only the water-tightness maintenance is completed well can constructors ensure that shrinkage is decreased or prevented at early stage. Concrete vibrating is quite significant for such shrinkage at early stage. Without concrete vibrating, it is fatal for subsequent crack resistance of concrete caused by obvious decrease of its strength and hardness when lots of pores appear inside concrete, although shrinkage of concrete may decrease. As a result, to maintain its durability at later stage, early concrete vibrating and water-tightness maintenance are needed for concrete.

\section{CONCLUSION}

From the experiment, it found that material property at early age greatly affects the durability latterly. Therefore, early concrete vibrating should be completed well which is the only way to characterize true durability and control its subsequent durability by control on its early material property.

\section{REFERENCES}

[1] Ba Songtao; Gong Jinxin; Tong Xiaoli, "Effect of Property of Concrete Material During Construction on Its Subsequent Durability,", Journal of Dalian University of Technology, 2014, (04).

[2] Fang Dongping; Gen Chuandong; Zhu Hongyi;Liu Xila, "Analysis on Effect of Property of Concrete Material During Construction on Its Subsequent Durability,", China Civil Engineering Journal, 2015, 35 (2).

[3] Sun Rong; Chen Zhonghan; Shao Yongiian; Zhen Chuanming, "Research on Effect of Property of Concrete Material on Its Subsequent Durability," Journal of Huazhong University of Science and Technology, 2016, (3). 